\title{
NUMERICAL STUDY OF WAVE RUN-UP AT PERMEABLE FIXED REVETMENT SLOPE
}

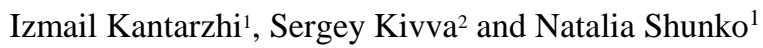

\begin{abstract}
The numerical model of wave surface elevation and water filtration in the saturated-unsaturated porous medium is developed. The model uses to define the parameters of the wave run-up at the slope protected by the permeable fixed layer. The model shows the wave surface in the different times, including the wave run-up height at the slope and wave run-down. Also, the velocities in the upper protected layer as well in the soil body of the slope are defined. Model is verified with using of the published large-scale tests with the slopes protected by Elastocoast technology layers. The tests were carried out in the wave flume of Technical University Braunschweig. The numerical model may be applied to calculate the maximal waves run-up at the protected engineering and beach slopes in natural conditions.
\end{abstract}

Keywords revetment slope; permeable polyurethane cover; wave run-up; water filtration; numerical modelling; large-scale tests comparison

\section{INTRODUCTION}

Protective permeable revetment slopes are widely used as in port construction and coastal protection. The existing calculation methods for multi-layer protective revetments cannot count such constructions due to the complexity of the theoretical description of the task interaction of waves with a slope.

As one of the modern technological solutions the technology Elastocoast, developed by German chemical concern BASF can be named.

The main idea of coastal protection technology Elastocoast is the construction on the surface of the beach or the construction of permeable revetment slope with open-pore of gravel or crushed stone, stuck between them. An important feature-no glue fills the pores completely between rubble and glues his only contact the individual elements of the rubble with each other. This makes it possible to attain the permeability of protective revetment.

The most detailed interaction of waves with plinth, protected by Elastocoast, studied in large-scale experiments at the Technical University of Braunschweig, Germany.

For an innovative idea to use Elastocoast technology in marine coastal protection with respect to folded gravel shores could be further developed in the framework of the present work was carried out numerical study of running up waves on the coastal slope, protected with Elastocoast technology.

For this numerical model, has been developed in the zone of wave propagation on a slope with permeable revetment in wave run-up area. The model was tested by the results of the large-scale experiments performed at the Technical University of Braunschweig, Germany.

To simulate the wave's run-up the mathematical model consisting of two submodels linked together, describing the movement of surface waters and the movement of moisture in saturated-unsaturated porous medium is constructed.

The developed numerical model of movement of surface waters and the movement of moisture in saturated-unsaturated porous medium allows to define the characteristics of the flow on a slope, sheltered in the run-up area by the permeable pinned layer. When this model establishes regulations free wave surface at different points in time, including the height of the run-up of waves on slope and height of waves at the run-down of a slope. In addition, the calculated velocity field of a fluid in the upper protective layer of a slope and moisture distribution in the body of the outgoing ground slope may be defined. The model is verified using published results of large-scale experiments performed in the wave tray at the Technical University of Braunschweig.

\section{RUN-UP OF WAVES ON THE IMPENETRABLE SLOPE Laboratory studies}

As the initial problem explores the run-up waves on an impermeable slope. As before, this case is a "control" for the task waves run-up on permeable protected slopes. Model of a coastal slope with the

\footnotetext{
${ }^{1}$ Department of Hydraulics and Hydraulic Structures, Moscow State University of Civil Engineering, 26 Yaroslavskoe Shosse, Moscow, 129337, Russia

2 Ukrainian Center of Environmental and Water Projects, 42 Glushkova Av., Kiev, 03187, Ukraine
} 
beach, was built at a scale of 1:25 in shallow pool of laboratory, across the entire width of the wave channel of $1.6 \mathrm{~m}$ (to exclude the effect of the impact basin walls) and along its axis (Fig. 1).

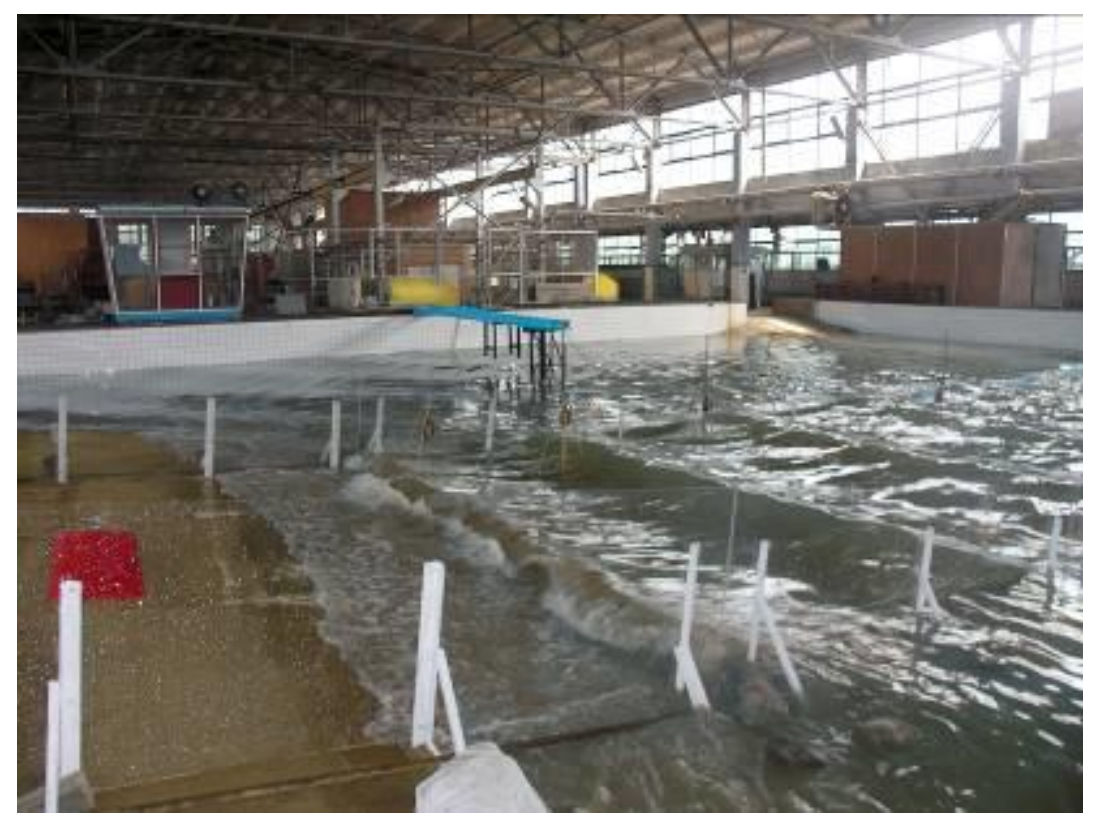

Figure 1. Experimental research of slope structures in wave basin

The width of the base of a coastal slope to the beach on a physical model was $5 \mathrm{~m}$, height $0.6 \mathrm{~m}$, slope angle 0.12 degrees. The width of the beach on the model, was $1.2 \mathrm{~m}$ and inclination 0.07 . Behind the beach model of not-moving was a coastal slope, width of $0.5 \mathrm{~m}$, and a height of $0,1 \mathrm{~m}$, at an angle to the horizon 0.2 degrees.

Waves generated by shield mobile wavemaker, installed on $3 \mathrm{~m}$ from the pool wall. Between the shallow pool wall and wavemaker the dissipater was placed. The width of the shield of wavemaker was $6 \mathrm{~m}$, height- $0.9 \mathrm{~m}$. On both sides of the wavemaker at $6 \mathrm{~m}$ installed fencing panels from acrylic glass, forming a wave channel length $18 \mathrm{~m}$, which ended for the model of a coastal slope. Model of a coastal slope began from $11 \mathrm{~m}$ from wavemaker.

Measurement of wave parameters in the process of experimental studies carried out instrumentally with the four capacitive sensors-wave measurers, whose signal cable system, over the surface of the water in the pool at special tripod mounted, acted on a personal computer, where carried out processing of measurement results according to a specially designed program. Wave measurers were located at 1.4 $\mathrm{m}, 2.9 \mathrm{~m}, 4.8 \mathrm{~m}$ and $7 \mathrm{~m}$ from water line (Fig. 1).

There have been three series of experiments, different parameters of the simulated storm and situation model. In the first series of experiments on model slope worked wave $13 \%$ exceedance, estimated the storm ( 1 times in 50 years), like a wave, equivalent to storms by the beach erosion.

\section{The first series of experiments.}

It was studied the effects of waves on coastal protection dam of construction project, located in front of the concrete slope the beach width $1.2 \mathrm{~m}$. Waves parameters, reproduced by the wavemaker were: wave height $-0.23 \mathrm{~m}$, length - $3.84 \mathrm{~m}$, period - 1,6s.

Table 1 presents the measured values of the amplitudes of the waves on wave measurers, where $d$ is the depth of the water, $\mathrm{L}_{\mathrm{b}}$ is distance between water level and wave measurer, $\mathrm{h}$ is the height of the waves.

The second series of experiments.

In the second series of experiments model subjected to processing the waves close to the maximum of $5 \%$ of exceedance estimated in the system of storm 1 times in 50 years.

Because in the scale 1:25 the waves of 5\% exceedance cannot be reproduced, experiments were conducted at a scale of 1:36 with the following parameters: wave height was $0.18 \mathrm{~m}$, length was $3.4 \mathrm{~m}$, period was $1.4 \mathrm{~s}$. The width of the beach, which was a model of protected coastal slope was $0.83 \mathrm{~m}$. 
Table 2 presents the measured values of the amplitudes of the waves on wave measurers, where $\mathrm{d}$ is the depth of the water, $\mathrm{L}_{\mathrm{b}}$ - distance between water level and the wave measurer, $\mathrm{h}$-wave height.

\begin{tabular}{|c|c|c|c|}
\hline \multicolumn{3}{|c|}{ Table 1. Measured values of the heights of waves in the first } \\
series of experiments. \\
\hline $\begin{array}{c}\text { No. of wave } \\
\text { measurer }\end{array}$ & $d, m$ & $L_{b, m}$ & $h, m$ \\
\hline 1 & 0.60 & 7.8 & $0.230 \pm 0.005$ \\
2 & 0.58 & 4.8 & $0.215 \pm 0.005$ \\
3 & 0.35 & 2.9 & $0.205 \pm 0.005$ \\
4 & 0.17 & 1.4 & $0.186 \pm 0.005$ \\
\hline
\end{tabular}

\begin{tabular}{|c|c|c|c|}
\hline \multicolumn{4}{|c|}{ Table 2. Measured values of the heights of waves in the second } \\
series of experiments. \\
\hline $\begin{array}{c}\text { No. of } \\
\text { wave } \\
\text { measurer }\end{array}$ & $d, m$ & $L_{b}, m$ & $h, m$ \\
\hline 1 & & & \\
2 & 0.60 & 7.8 & $0.183 \pm 0.01$ \\
3 & 0.58 & 4.8 & $0.184 \pm 0.01$ \\
4 & 0.35 & 2.9 & $0.173 \pm 0.01$ \\
& 0.17 & 1.4 & $0.197 \pm 0.01$ \\
\hline
\end{tabular}

\section{The third series of experiments.}

In the third series of experiments investigated effects of the waves 1 times per year on the no moving model of a coastal slope, located behind the beach model with width $1.2 \mathrm{~m}$. The aim was to show the influence of the small waves that can move along the beach slope more carefully than large waves. Experiments were performed in the scale 1:25. Parameters of the waves, reproducible by wavemaker were: wave height is $0.11 \mathrm{~m}$, length is $3.84 \mathrm{~m}$, period is $1.63 \mathrm{~s}$.

Table 3 presents the measured values of the amplitudes of the waves on wave measurers, where $d$ is the depth of the water, $\mathrm{L}_{\mathrm{b}}$ is the distance between water level and wave measurer, $\mathrm{h}$ is wave height.

\begin{tabular}{|c|c|c|c|}
\hline \multicolumn{4}{|c|}{ Table 3. Measured values of the heights of waves in the third } \\
series of experiments. \\
\hline $\begin{array}{c}\text { No. of } \\
\text { wave } \\
\text { measurer }\end{array}$ & $d, m$ & $L b, m$ & $h, m$ \\
\hline 1 & 0.60 & 7.8 & $0.113 \pm 0.005$ \\
\hline 2 & 0.58 & 4.8 & $0.104 \pm 0.005$ \\
\hline 3 & 0.35 & 2.9 & $0.082 \pm 0.005$ \\
\hline 4 & 0.17 & 1.4 & $0.109 \pm 0.005$ \\
\hline
\end{tabular}

\section{Numerical simulation}

Modeling of transformation waves on slopes for the parameters of model studies by nonlinear numerical model based on equations of Boussinesq-Jeleznyak-Pelinovsky (Serres) with special additives. Basic equations of numerical model are listed below [Jeleznyak and Pelinovsky. 1985]:

$$
\begin{aligned}
& H_{t}+(H u)_{x}+(H v)_{y}=0, \\
& u_{t}+u u_{x}+v u_{y}+g \eta_{x}+ \\
& +\left(\alpha_{2}-\alpha_{1}\right) h^{2}\left[u_{t x x}+v_{t x y}+\left(u u_{x}\right)_{x x}+\left(v u_{y}\right)_{x x}+\left(u v_{x}\right)_{x y}+\left(v v_{y}\right)_{x y}+g \eta_{x x x}+g \eta_{x y y}\right]- \\
& -\alpha_{2} h\left[\left(h u_{t}\right)_{x x}+\left(h v_{t}\right)_{x y}+\left(h u u_{x}\right)_{x x}+\left(h v u_{y}\right)_{x x}+\left(h u v_{x}\right)_{x y}+\left(h v v_{y}\right)_{x y}+g\left(h \eta_{x}\right)_{x x}+g\left(h \eta_{y}\right)_{x y}\right]= \\
& =\frac{1}{H}\left[\frac{H^{3}}{3} R+\frac{H^{2}}{2} Q\right]_{x}-h_{x}\left(\frac{H}{2} R+Q\right) \\
& v_{t}+u v_{x}+v v_{y}+g \eta_{y}+ \\
& +\left(\alpha_{2}-\alpha_{1}\right) h^{2}\left[u_{t x y}+v_{t y y}+\left(u u_{x}\right)_{x y}+\left(v u_{y}\right)_{x y}+\left(u v_{x}\right)_{y y}+\left(v v_{y}\right)_{y y}+g \eta_{x y}+g \eta_{y y}\right]- \\
& -\alpha_{2} h\left[\left(h u_{t}\right)_{x y}+\left(h v_{t}\right)_{y y}+\left(h u u_{x}\right)_{x y}+\left(h v u_{y}\right)_{x y}+\left(h u v_{x}\right)_{y y}+\left(h v v_{y}\right)_{y y}+g\left(h \eta_{x}\right)_{x y}+g\left(h \eta_{y}\right)_{y y}\right]= \\
& =\frac{1}{H}\left[\frac{H^{3}}{3} R+\frac{H^{2}}{2} Q\right]_{y}-h_{y}\left(\frac{H}{2} R+Q\right)
\end{aligned}
$$


where

$$
\begin{aligned}
& R=u_{x t}+v_{y t}+u u_{x x}-u_{x}^{2}+v v_{y y}-v_{y}^{2}+v u_{x y}+u v_{x y}-2 u_{x} v_{y}, \\
& Q=h_{x} u_{t}+h_{y} v_{t}+h_{x} u u_{x}+h_{v} v v_{y}+h_{x x} u^{2}+h_{y y} v^{2}+h_{y} u v_{x}+h_{x} v u_{y}+2 h_{x y} u v
\end{aligned}
$$

In shallow water theory, there is no dependence of the velocity of water depth, but when plotting equations the hypotheses used about the distribution of pressure in depth. In the classic (without dispersion) theory of shallow water pressure changes by the hydrostatic law with disregard for the influence of flow speeds on the pressure distribution. Obtained in this approach, the equations do not take into account the dispersion - dependence of the speed of waves from its length.

The equations of nonlinear dispersion theory (Boussinesq-type equations) are already taken into account the contribution of the vertical accelerations on the vertical wave pressure distribution the equations [Jeleznyak and Pelinovsky. 1985] take into account wave dispersion.

The equations of nonlinear dispersion models of shallow water apply to describe as long waves, for which the dispersion effects are weak (which follows from the dispersion relation of linear wave theory) and shorter waves than the nonlinear equations without dispersion ("classical") theory of shallow water. Similarly, the accepted model equation, taking into account the influence of wave velocity on the vertical pressure distribution, have a wider applicability than the "classic" equations of nonlinear shallow water theory.

Asked the following parameters: $\alpha_{1}=1 / 17.5, \alpha_{2}=1 / 10$. Introduced with the coefficient of Chézy bottom friction, equal to $60 . \mathrm{H}_{\mathrm{rms}}$ was calculated - RMS wave height during the period:

$$
H_{r m s}=\frac{2}{T} \sqrt{\int_{t_{0}}^{t_{0}+T} \eta^{2} d t},
$$

where $\eta$ is the free surface elevation.

For the first series of experiments (waves, reproducible by wavemaker were: wave height $0.23 \mathrm{~m}$, length-3.84 m, period-1.6 s) comparison of calculations and measurements shown in table 4, and the results of numerical simulation provides in Fig. 2.

1.

Table 4. The measured and calculated values of the heights of the waves, the first series.

\begin{tabular}{|c|c|c|c|c|}
\hline $\begin{array}{c}\text { No. of } \\
\text { wave } \\
\text { measurer }\end{array}$ & $d, m$ & $L_{b,} m$ & $\begin{array}{c}\text { Measured } \\
h, m\end{array}$ & $\begin{array}{c}\text { Numerical } \\
\text { simulation } \\
H_{\text {rms }} m\end{array}$ \\
\hline 1 & 0.60 & 7.8 & $0.230 \pm 0.005$ & 0.231 \\
2 & 0.58 & 4.8 & $0.215 \pm 0.005$ & 0.218 \\
3 & 0.35 & 2.9 & $0.205 \pm 0.005$ & 0.200 \\
4 & 0.17 & 1.4 & $0.186 \pm 0.005$ & 0.179 \\
\hline
\end{tabular}

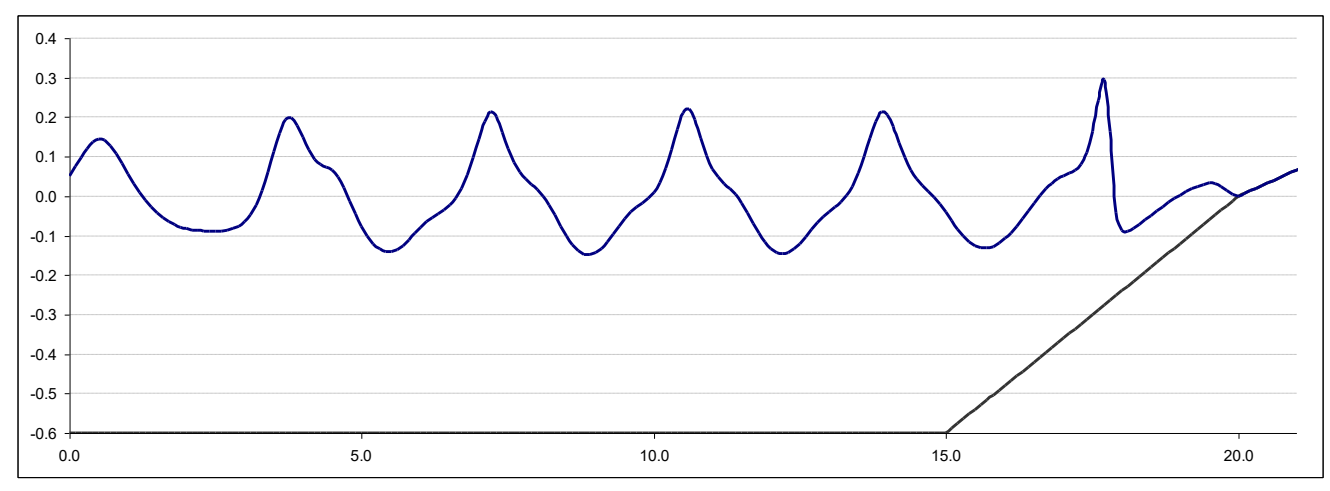




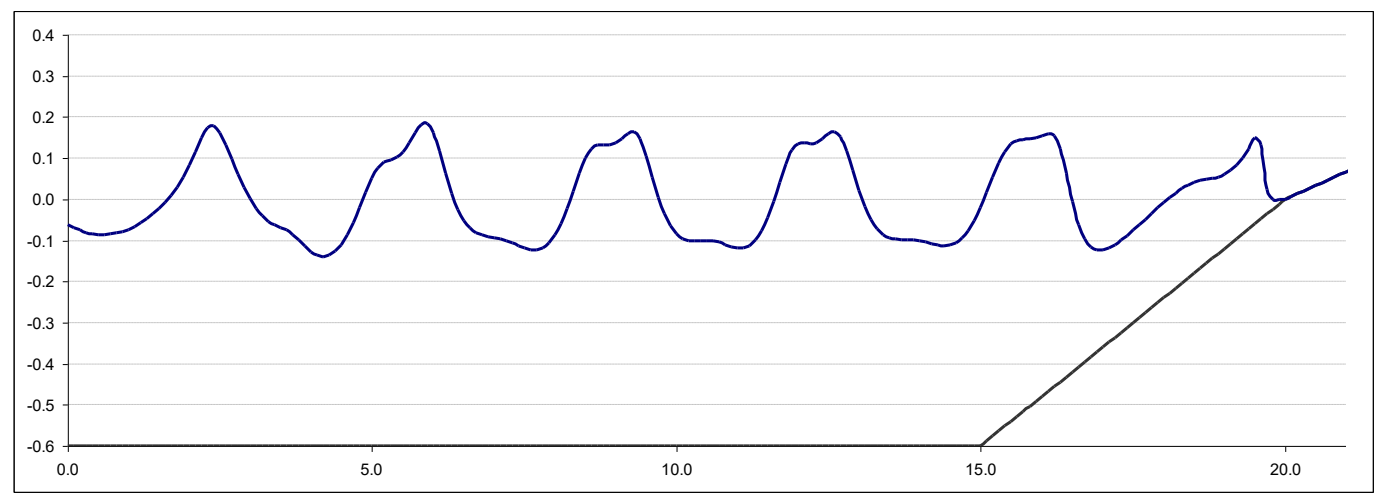

Figure 2. The transformation of waves for experiments of $1^{\text {st }}$ series according to the results of numerical simulation. Horizontally-wave ray distance $(m)$, vertically- wave surface elevation $(m)$

The results of numerical experiments quite satisfactorily consistent with measured wave heights (Table 4). Waves run-up in numerical experiments barely protected at the foot of the slope, as with physical modeling. Increasing of waves when approaching the breaking, as well as on the model.

On the second series of experiments (wave marker: wave height- $0.18 \mathrm{~m}$, length-3.4 m, period 1.4s) comparison of calculated and measured wave heights are shown in Table 5, and instant surface wave profiles in Fig.3.

\begin{tabular}{|c|c|c|c|c|}
\hline \multicolumn{5}{|c|}{ Table 5. The measured and calculated values of the heights of the } \\
waves. Second series
\end{tabular}

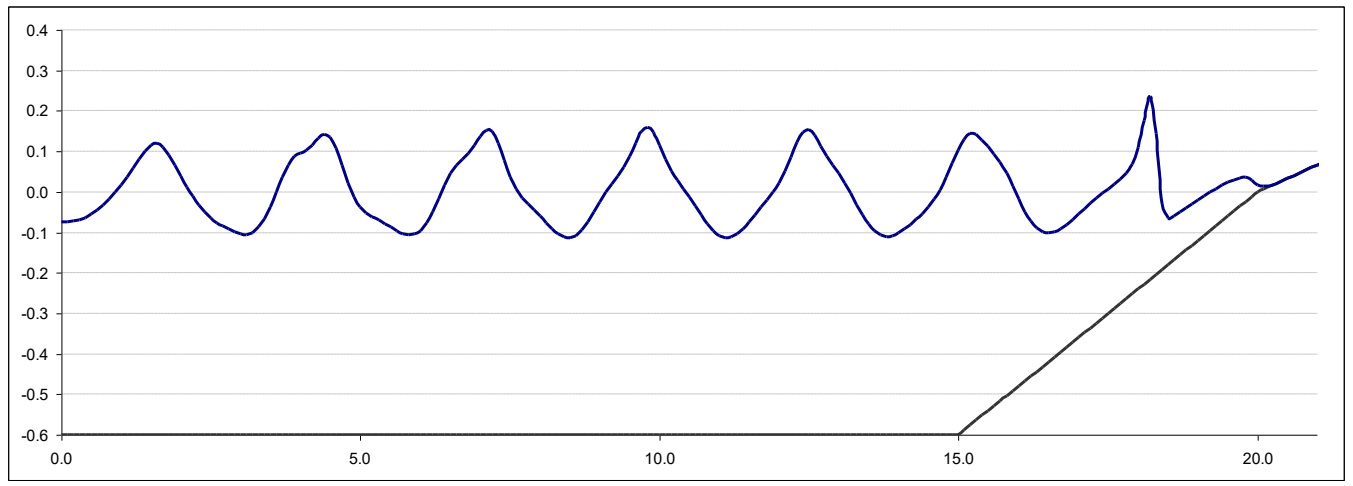




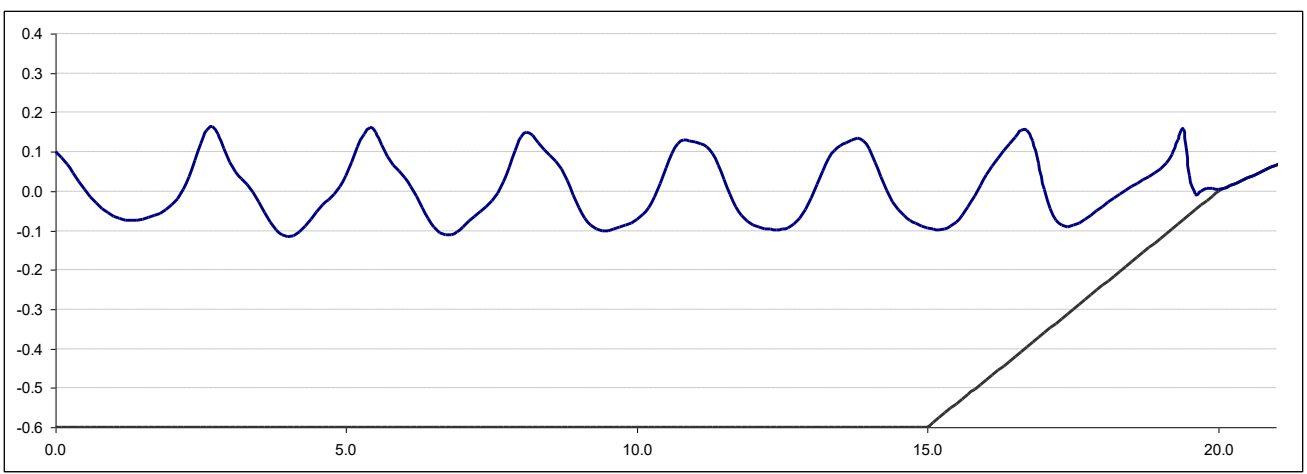

Figure 3. Transformation of waves for $2^{\text {nd }}$ series, result of numerical simulation. Horizontally-wave ray distance $(m)$, vertically- wave surface elevation $(m)$

Settlement agreement with measurements of wave heights again is quite satisfactory. In this case (high wave) run-up reaches the protected part of the berm. Waves significantly transformed when driving on a slope.

On the third series of experiments (wave height- $0.11 \mathrm{~m}$, length-3.84 m, period-1.63 s) comparison is shown in Table 6, and instant surface wave profiles in Fig. 4.

\begin{tabular}{|c|c|c|c|c|}
\hline \multicolumn{5}{|c|}{$\begin{array}{l}\text { Table 6. The measured and calculated values of the heights of th } \\
\text { waves, third series }\end{array}$} \\
\hline $\begin{array}{l}\text { No. of } \\
\text { wave } \\
\text { measurer }\end{array}$ & $H, m$ & $L_{b}, m$ & $\begin{array}{l}\text { measured } \\
\qquad h_{8}, m\end{array}$ & $\begin{array}{c}\text { Numerical } \\
\text { simulation } \\
H_{r m s} m\end{array}$ \\
\hline 1 & 0.60 & 7.8 & $0.113 \pm 0.005$ & 0.107 \\
\hline 2 & 0.58 & 4.8 & $0.104 \pm 0.005$ & 0.104 \\
\hline 3 & 0.35 & 2.9 & $0.082 \pm 0.005$ & 0.094 \\
\hline 4 & 0.17 & 1.4 & $0.109 \pm 0.005$ & 0.109 \\
\hline
\end{tabular}

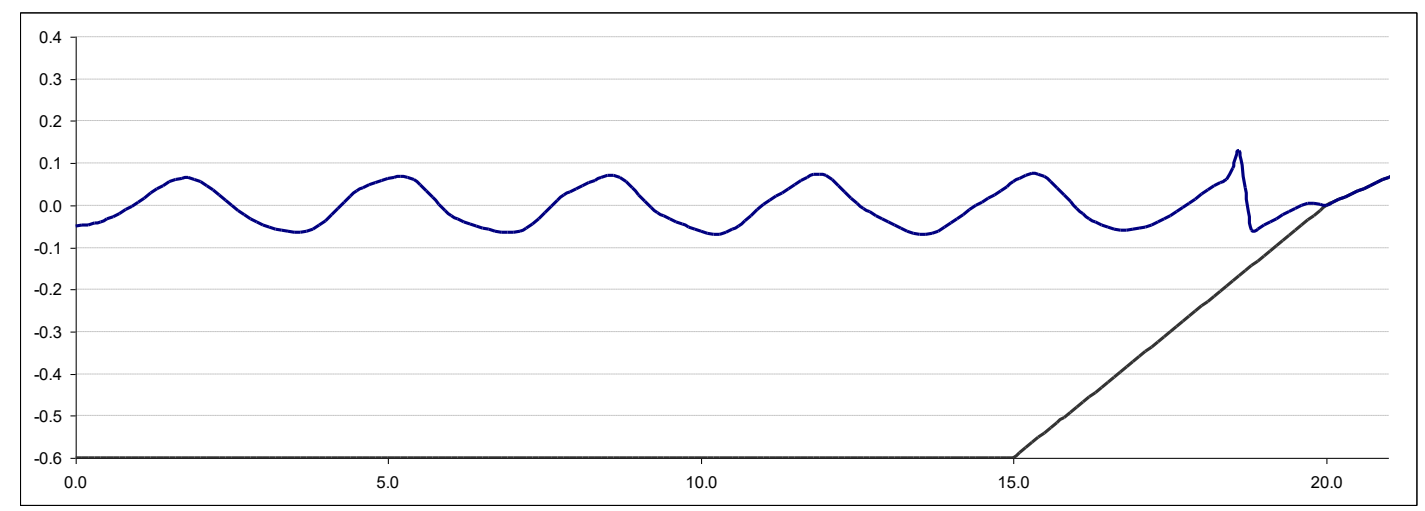




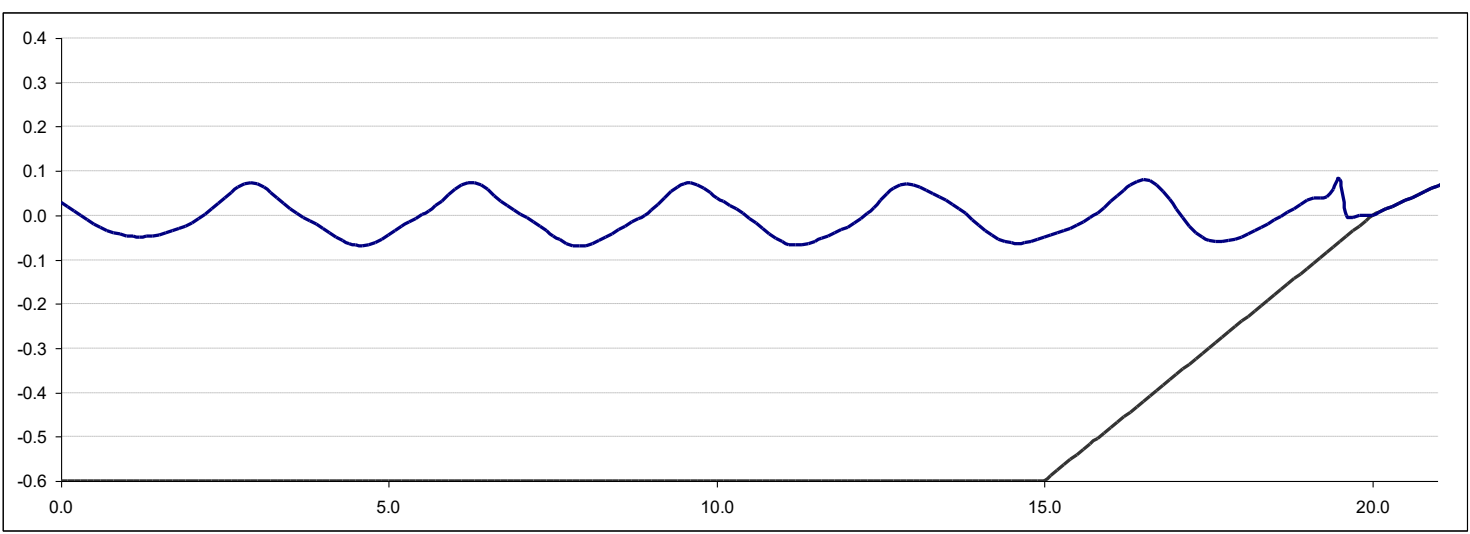

Figure 4. Transformation of waves for experiments of $3^{\text {rd }}$ series based on the results of numerical simulation. Horizontally-wave ray distance $(m)$, vertically- wave surface elevation $(m)$

Because of this series of experiments: the consent of calculations and measurements of the waves is satisfactory, run-up of waves does not reach a concrete slope, waves weakly transformed to form when driving on a slope.

The aggregate of all data carried out measurements and calculations, built regression dependence of the measured and calculated heights waves in tables 4, 5, and 6 above. The results are shown in Table 7 and Fig. 5. The correlation coefficient of the measured and calculated heights of waves: $\mathrm{R}=$ 0.985 , indicating good acceptance of the results of physical and numerical modeling.

\begin{tabular}{|l|c|c|}
\hline \multicolumn{3}{|c|}{$\begin{array}{l}\text { Table 7. Measured and calculated the } \\
\text { height of the waves for all experiments, } \mathbf{m}\end{array}$} \\
\hline \multicolumn{3}{|c|}{ experiment model } \\
\hline Series 1 & 0.230 & 0.231 \\
\hline \multirow{4}{*}{} & 0.215 & 0.218 \\
\cline { 2 - 3 } & 0.205 & 0.2 \\
\cline { 2 - 3 } & 0.186 & 0.179 \\
\hline Series 2 & 0.183 & 0.201 \\
\hline \multirow{5}{*}{} & 0.184 & 0.184 \\
\cline { 2 - 3 } & 0.173 & 0.186 \\
\cline { 2 - 3 } & 0.197 & 0.187 \\
\hline Series 3 & 0.113 & 0.107 \\
\hline & 0.104 & 0.104 \\
\hline & 0.082 & 0.094 \\
\cline { 2 - 3 } & 0.109 & 0.109 \\
\hline
\end{tabular}




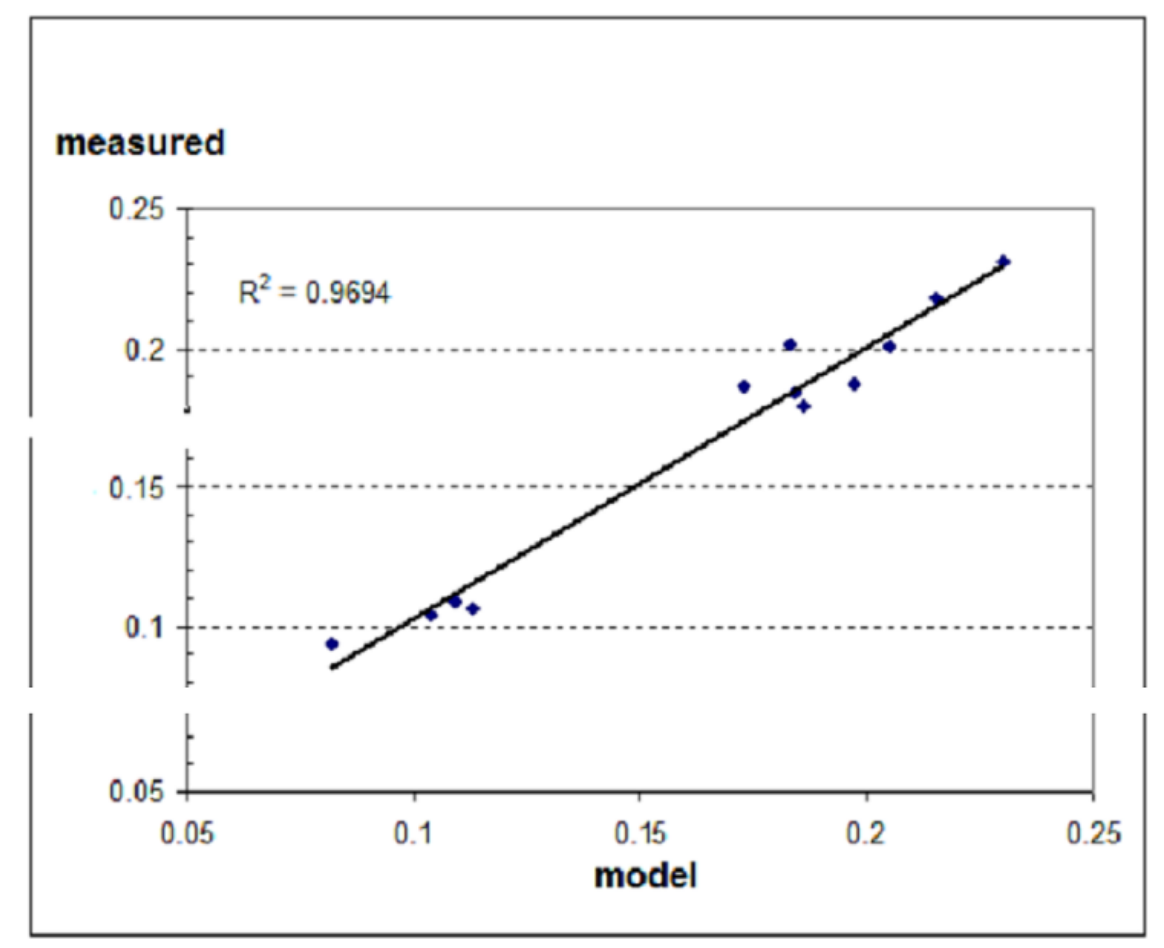

Figure 5. Wave height received physical and numerical modelling. Comparison

Thus, it is shown that the nonlinear dispersive long-wave model satisfactorily describes the run-up of waves on impermeable slopes. And it can be expected that such models can be used for numerical simulation of run-up of waves on permeable slopes.

\section{Using of cover Elastocoast}

Permeable constructions of slope profile with rubble mound protective coatings are widely used both in port construction and coastal protection. In view of the complexity of the theoretical description of the task interaction of waves with external coverings bank structures, there are certain difficulties in their design [Lappo, Strekalov, Zavialov. 1990; Alcerreca and Oumeraci. 2012; Didier and Neves. 2009; Hughes. 2004]. As an alternative to the existing design solutions, as well as further development of calculation methods of wave loads, it may be considered one of modern technological solutions. It is based on the application of technology Elastocoast [The Elastocoast System. 2008]), which is developed by the German chemical concern BASF.

Elastocoast system represents a new type of protective coating that can be applied in the zone of action of waves and splash zone or on the inner slopes of dams. This coverage consists of mound material and polyurethane. Each stone is covered with a thin film of polyurethane. Having hardened, the film brings the stones put together only at contact points. When the spaces between the stones remain to be filled, that ensures openness and permeability of the coating structure. This technology has been successfully applied in Western Europe, in many objects [Experimental Projects with Elastocoast System in Holland in Storm Period 2007/2008. 2008; The Elastocoast System. 2008] (Fig.6).

It should be noted that studies on wave impact on such sloping protective coating utilized only with waves up to $1.5 \mathrm{~m}$. Study of wave loads on protective coating for the sea coast with pebbly beaches, where waves can be calculated in $4 \div 5$ times more was not carried out. Therefore, the method of calculation for such conditions to be further developed. Therefore, it seems necessary to conduct research with the development of a mathematical model of the interaction of waves with slope covered with Elastocoast system. For verification of calculation methods and numerical models, it is advisable to use the results of existing experimental studies on the effects of waves on the protective covering of slopes, executed with application of Elastocoast technologies [Hydraulic Performance, Wave Loading and Response of Elastocoast and their Foundation. A Large-Scale Model Study (Final Report). 2010; 
Compilation of the Technical Design Guidelines for Elastocoast. 2010 ].

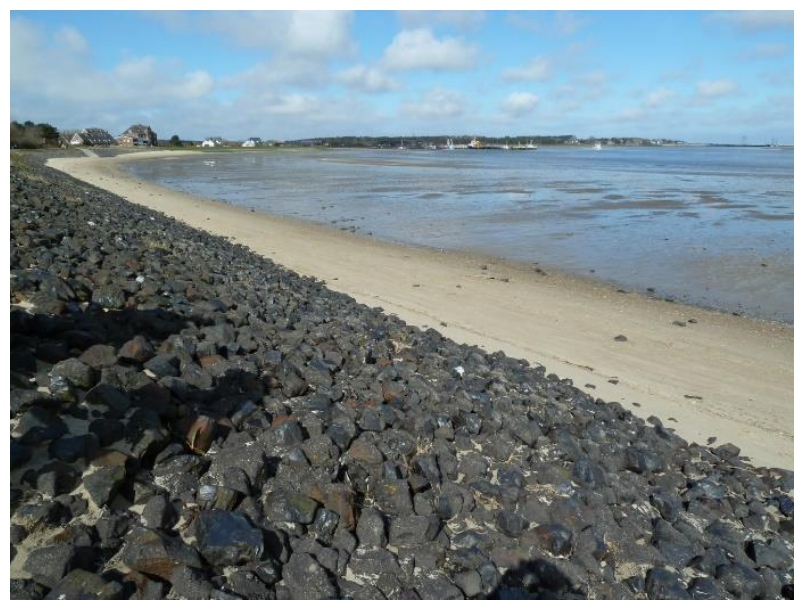

Figure 6. Coastal protection slope using Elastocoast technology on Amrum inland in the North Sea

Thus, the objective of these studies is to develop numerical models of waves run-up on permeable protected slope and proof of its applicability for slopes, covered with Elastocoast system by comparing with the data of the experiments. In the future, with binding method at any time to the phase of a wave, it will be possible to obtain a new method of calculating wave loads on high permeable structure with coating. The results of this research will be applied in the development of new effective constructions of the slope profile, capable of resisting the effects of stormy excitement.

Setting characteristics of protective coating, using a numerical model can be measured the height of waves on slope and roll wave loads, which will be subject to coverage in storm periods. This will set the design characteristics that define its coverage strength and endurance, as well as reasonably assign top stamp (above-water part) constructions. In addition, the acquired data, will provide the opportunity to calculate the distributions of wave pressure and counter pressure on the permeable cover bank structures.

The closest research in this area are the experiences of experts on the interaction of waves with protective structures roble mound type [Liebisch et al. 2012; Muttray et al.1998; Muttray and Oumeraci. 2005]. Known modelling techniques of waves run-upon an impermeable slope [Jeleznyak et al. 2011] and methods of calculation of running waves on the ground and mound slopes [Kantardgi, Kivva, and Shunko. 2014]. All these activities indicator height running waves on slope was the main criterion for research. However, such studies need improvement and development in accordance with the specific goal of the present work tasks. First, this relates to the accounting of the pore water movement that occurs in a relatively thin surface protective layer.

\section{Experiences with Elastocoast protection in a large wave flume}

The most detailed interaction of waves with slope, protected coating Elastocoast, studied in largescale experiments, [Hydraulic Performance, Wave Loading and Response of Elastocoast and their Foundation. A Large-Scale Model Study (Final Report). 2010; Oumeraci. 2012] as described below. These experiments will be used to verify further developed numerical models.

Experiments were conducted in a large wave flume in Hannover, Germany. Installation length approx. $300 \mathrm{~m}$ and width of about $5 \mathrm{~m}$, height of the walls to $7 \mathrm{~m}$ allows you to have up to $5 \mathrm{~m}$ water depth, that allows you to generate a regular wave height up to $2 \mathrm{~m}$ and wave spectrum with a significant wave height of up to $1.3 \mathrm{~m}$. Facility also allows you to receive single waves with a height of about $1 \mathrm{~m}$ and wave-killer (focusable) waves of up to $2.5 \mathrm{~m}$. Wave generator has a good absorbing control to ensure permanent wave parameters experience for a long time.

The large size of the wave flume allows the study of the protective coating of slope in the field scale. This is fundamentally important to the problem since the strength properties of the coating in the flume did not simulate under scaling.

The model schema in a large wave flume with slope, protected coating Elastocoast, is shown in Figure 7. 


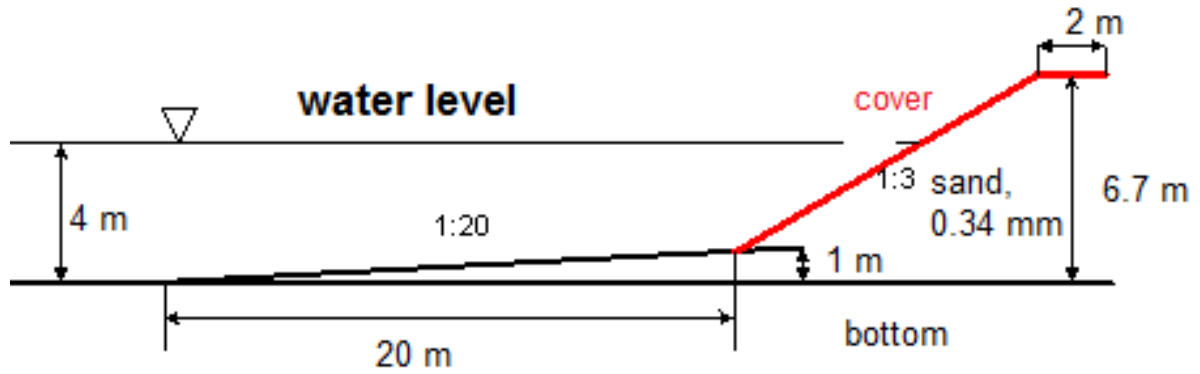

Figure 8. A schematic of the experimental setup in a large wave flume of Technical University Braunschweig

In experiments [Hydraulic Performance, Wave Loading and Response of Elastocoast and their Foundation. A Large-Scale Model Study (Final Report), 2010] three different cover slope investigated outlined as model A, model B and model C.

mocel A

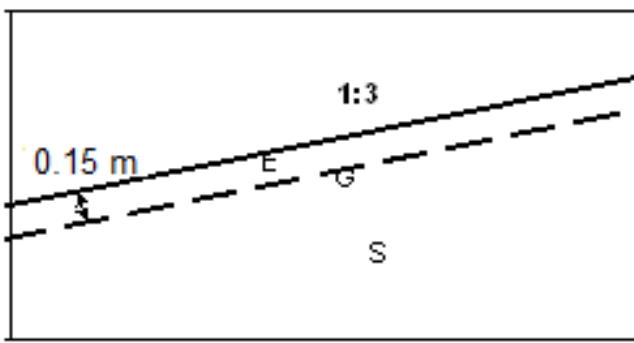

Model $\mathrm{B}$

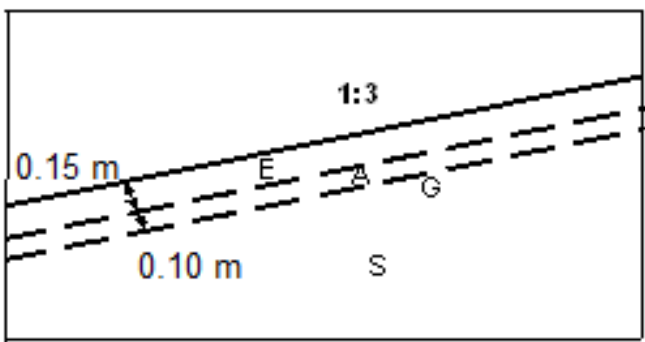

Model C

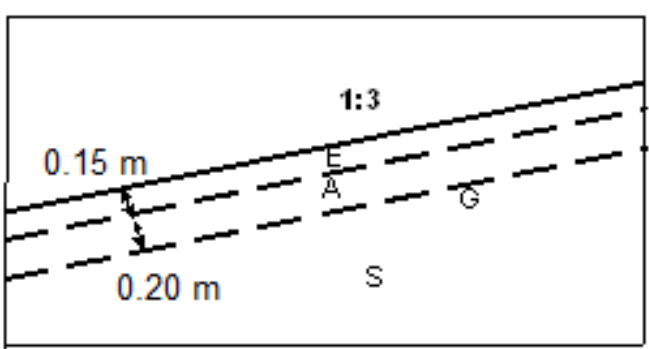

Figure 8. Cover slopes in the flume experiments

E-coating system Elastocoast, thickness of $0.15 \mathrm{~m}$, filler-lime crushed stone, size $\mathbf{2 0 - 4 0} \mathrm{mm}$, for model with granite was used, size $16-36 \mathrm{~mm}$ (porosity 0.388 );

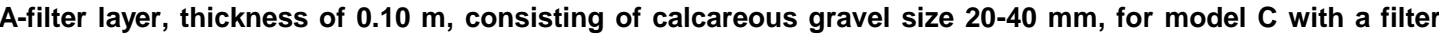
layer amounted to $0.20 \mathrm{~mm}$, with a filling of granite macadam, size $16-36 \mathrm{~mm}$;

G-stamps geotextiles layer "Terrafix 609" hydraulic permeability $4.7 \cdot 10^{-3} \mathrm{~m} / \mathrm{s}$;

S-sandy basis, $D_{50}=0.34 \mathrm{~mm}, D_{60} / D_{10}=2.11$, hydraulic permeability $4.7 \cdot 10^{-4} \mathrm{~m} / \mathrm{s}$. 
About the destruction of the cover while increasing wave height in experiments, experiments on this cover was carried out only partially. Wave modes in experiments with regular waves are presented in Table 8 .

\begin{tabular}{|c|c|c|c|c|c|c|c|}
\hline No. of test & $\begin{array}{c}H_{\text {nom }}, \\
\mathrm{m}\end{array}$ & $\begin{array}{c}T_{\text {nom }} \\
\mathrm{s}\end{array}$ & $\begin{array}{l}h, \\
\mathrm{~m}\end{array}$ & $\begin{array}{c}H_{m} \\
\mathrm{~m}\end{array}$ & $\begin{array}{c}T_{m} \\
\mathrm{~s}\end{array}$ & $C_{r}$ & $\xi_{m}$ \\
\hline 1 & 2 & 3 & 4 & 5 & 6 & 7 & 8 \\
\hline 09051301 & 0.2 & 3 & 3.4 & 0.22 & 3.00 & 0.339 & 2.67 \\
\hline 09051302 & 0.2 & 4 & 3.4 & 0.19 & 4.00 & 0.621 & 3.77 \\
\hline 09051303 & 0.2 & 5 & 3.4 & 0.21 & 5.00 & 0.682 & 4.59 \\
\hline 09051401 & 0.2 & 6 & 3.4 & 0.18 & 5.93 & 0.734 & 5.78 \\
\hline 09051402 & 0.2 & 7 & 3.4 & 0.22 & 7.00 & 0.782 & 6.24 \\
\hline 09051403 & 0.2 & 8 & 3.4 & 0.17 & 7.90 & 0.860 & 7.94 \\
\hline 09051404 & 0.6 & 3 & 3.4 & 0.65 & 3.00 & 0.127 & 1.55 \\
\hline 09051405 & 0.6 & 4 & 3.6 & 0.68 & 4.01 & 0.292 & 2.02 \\
\hline 09051406 & 1.0 & 3 & 3.6 & 1.04 & 3.00 & 0.183 & 1.22 \\
\hline 09051501 & 0.6 & 5 & 3.7 & 0.64 & 4.95 & 0.487 & 2.57 \\
\hline 09051502 & 1.0 & 4 & 3.7 & 1.14 & 3.92 & 0.161 & 1.53 \\
\hline 09051503 & 1.3 & 4 & 3.7 & 1.40 & 3.92 & 0.143 & 1.38 \\
\hline 09051504 & 0.6 & 6 & 3.9 & 0.65 & 6.00 & 0.581 & 3.10 \\
\hline 09051505 & 0.6 & 7 & 3.9 & 0.54 & 6.93 & 0.665 & 3.91 \\
\hline 090511801 & 0.6 & 8 & 3.9 & 0.55 & 7.98 & 0.695 & 4.49 \\
\hline 090511802 & 1.3 & 5 & 3.9 & 1.37 & 4.90 & 0.155 & 1.75 \\
\hline 09060501 & 0.2 & 3 & 3.4 & 0.22 & 2.99 & 0.332 & 2.65 \\
\hline 09060502 & 0.2 & 5 & 3.4 & 0.20 & 5.00 & 0.678 & 4.66 \\
\hline 09060503 & 0.2 & 8 & 3.4 & 0.17 & 8.00 & 0.863 & 8.05 \\
\hline 09060504 & 0.6 & 3 & 3.4 & 0.66 & 3.00 & 0.091 & 1.54 \\
\hline 09060505 & 0.6 & 4 & 3.6 & 0.69 & 4.00 & 0.289 & 2.00 \\
\hline 09061803 & 0.6 & 5 & 3.8 & 0.58 & 4.99 & 0.521 & 2.72 \\
\hline 09061804 & 0.6 & 6 & 3.9 & 0.72 & 6.00 & 0.567 & 2.95 \\
\hline 09061805 & 0.6 & 7 & 3.9 & 0.52 & 6.99 & 0.633 & 4.02 \\
\hline 09062301 & 0.5 & 7 & 3.8 & 0.44 & 7.00 & 0.731 & 4.39 \\
\hline 09062302 & 0.4 & 8 & 3.7 & 0.50 & 7.99 & 0.731 & 4.72 \\
\hline 09062303 & 0.7 & 3 & 3.5 & 0.67 & 3.00 & 0.102 & 1.53 \\
\hline 09062304 & 0.8 & 3 & 3.5 & 0.75 & 3.00 & 0.119 & 1.44 \\
\hline 09062305 & 0.9 & 3 & 3.5 & 0.84 & 3.00 & 0.152 & 1.36 \\
\hline 09062306 & 1.0 & 3 & 3.5 & 0.92 & 3.01 & 0.105 & 1.31 \\
\hline 09062307 & 0.4 & 3 & 3.4 & 0.39 & 3.00 & 0.241 & 1.99 \\
\hline 09062308 & 0.5 & 3 & 3.4 & 0.49 & 3.00 & 0.228 & 1.79 \\
\hline 09062912 & 1.0 & 5 & 3.9 & 1.01 & 5.01 & 0.358 & 2.08 \\
\hline 09062913 & 1.0 & 6 & 4.1 & 0.92 & 6.02 & 0.496 & 2.61 \\
\hline 09062914 & 1.3 & 6 & 4.2 & 1.24 & 6.03 & 0.406 & 2.25 \\
\hline 09062915 & 1.0 & 7 & 4.2 & 1.17 & 7.02 & 0.541 & 2.70 \\
\hline 09062916 & 1.0 & 8 & 4.2 & 0.91 & 8.05 & 0.689 & 3.52 \\
\hline
\end{tabular}

Legend: $\mathrm{H}_{\text {nom-set }}$ wave height, wave period set- $\mathrm{T}_{\text {nom }}$, $\mathrm{h}$ is the water depth, $\mathrm{H}_{\mathrm{m}}$-height of the waves at the foot of the slope, $\mathrm{T}_{\mathrm{m}}$-period waves at the foot of the slope, $\mathrm{C}_{\mathrm{r}}$-wave reflection coefficient, $\xi_{m}=\frac{\operatorname{tg} \alpha}{\sqrt{H_{m} / L_{0}}}$ - parameter similarity of surf zone, $L_{0}=\frac{g T}{2 \pi}$ length of waves on deep water.

Characteristics definition schema of wave run-up on slope is shown in Fig. 9.

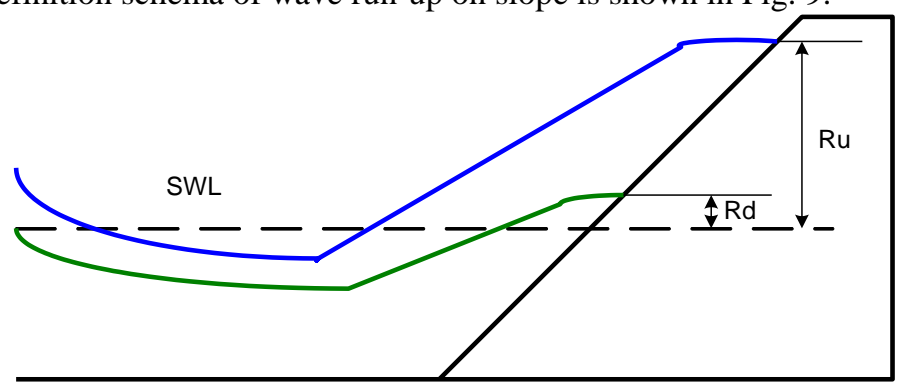

Figure 9. Run-up/run-down definition schema on slope, $\mathbf{R}_{u}$-height of run-up, $\mathbf{R}_{d}$ is the height of the rundown, SWL-water surface level 
To approximate the results of experiments in [Hughes S.A. 2004] were used the following dependencies:

Model B

$$
\begin{aligned}
& \frac{\mathrm{R}_{\mathrm{u}}}{\mathrm{H}_{\mathrm{m}}}=0,54[1,65 \xi], \xi<2,7 \\
& \frac{\mathrm{R}_{\mathrm{u}}}{\mathrm{H}_{\mathrm{m}}}=0,78\left[4,0-\frac{1,5}{\sqrt{\xi}}\right], \xi \geq 2,7
\end{aligned}
$$

Модель С

$$
\begin{aligned}
& \frac{\mathrm{R}_{\mathrm{u}}}{\mathrm{H}_{\mathrm{m}}}=0,52[1,65 \xi], \xi<2,7 \\
& \frac{R_{u}}{H_{m}}=0,76\left[4,0-\frac{1,5}{\sqrt{\xi}}\right] \xi \geq 2,7
\end{aligned}
$$

Experimentally it has been found that experienced values of wave run-up on slope coated by B cover in is not significantly different from the values of the wave run-up on the slope with cover C. Experiments indicated the same substantial lowering of the wave run-up on slope with permeable coating, if compared to the wave run-up on the smooth impermeable slope. The difference in the data depended on setting $\xi$ and was for relative surge $R_{l} / H_{m}$ from $25 \%$, for large values of up to $50 \%$ for smaller values of $\xi$.

\section{Mathematical model of waves run-up on slope protected by permeable fixed coating.}

Within the framework of solving the problem of the applicability of the Elastocoast system for marine shores with pebbly beaches, numerical study was conducted of the coastal waves running the slope. The developed model was tested for the results of the large-scale experiments performed at the Technical University of Braunschweig, Germany. The mathematical model consists of two submodels linked together, describing the movement of surface waters and the movement of moisture in saturatedunsaturated porous (the water level under the cover). The model scheme is presented in Fig.10.

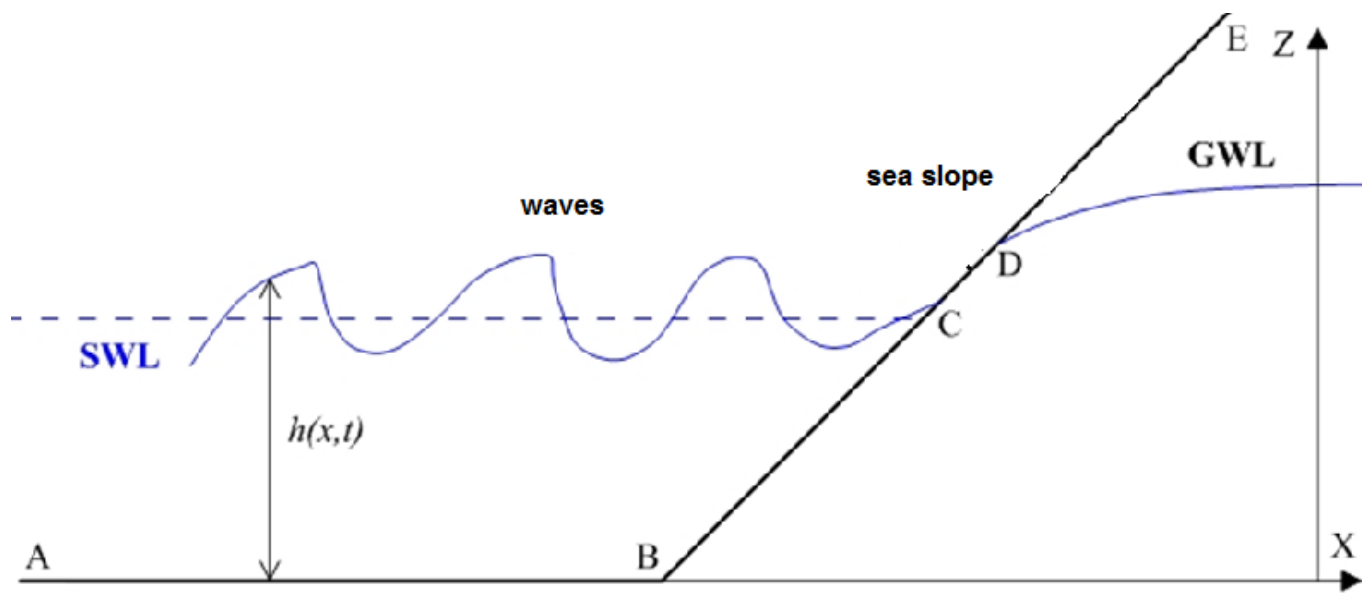

Figure 10. Schematic of waves run-up on slope in numerical model

The equations of motion of the water with a free surface were obtained by integrating the NavierStokes equations for the flow depth using kinematic boundary conditions. These equations include the equation of continuity and momentum equations. They can be written in the following format:

$$
\frac{\partial h}{\partial t}+\frac{\partial}{\partial x_{i}}\left(u_{i} h\right)=I,(4)
$$




$$
\frac{\partial}{\partial t}\left(u_{i} h\right)+\frac{\partial}{\partial x_{j}}\left(u_{j} u_{i} h\right)+g h \frac{\partial \xi}{\partial x_{i}}+g \frac{n^{2}}{h^{4 / 3}} u_{i}|u|=0
$$

where $\mathrm{t}$ is the time; $x_{i}$ are the spatial coordinates; $h=\xi-\eta$ is the depth of flow; $u_{i}$ is the flow velocity in the direction $x_{i} ; \xi(x, t)$ is the equation of free surface; $\eta(x, t)$ is the bottom equation; $\mathrm{g}$ is the gravitational acceleration; $\mathrm{n}$ is the Manning roughness coefficient; I is infiltration.

It is assumed that water movement in saturated-unsaturated porous media occurs under the influence of the force of gravity is proportional to the gradient of pressure per the generalized Darcy's law. Porous media seen as deformable and liquid as no compressed.

The term "saturated-unsaturated porous media" is the accepted term for more than 40 years. This term refers to porous media, one of which part is not saturated with moisture, and the other is full. Border section of these parts is unknown in advance and must be defined. Unsaturated soil moisture movement describes by a generalized law of Darcy, which in this case is non-linear, in contrast to an eventful occasion where it is linear.

It is considered that the movement of water in gaseous form can be neglected. Then, ignoring the hysteresis and temperature gradients, water movement in unsaturated-saturated porous media can be described by the equation:

$$
\frac{\partial}{\partial t}(\phi S)=\frac{\partial}{\partial x_{i}}\left[\frac{k_{r} k_{i j}}{\mu}\left(\frac{\partial p}{\partial x_{j}}+g \rho \frac{\partial z}{\partial x_{j}}\right)\right],
$$

where $t$ is the time, $x_{i}$ are the Cartesian spatial coordinates, $\phi$ is the volumetric porosity, $\rho$ is the density of porous moisture, $k_{i j}$ are the coefficient of permeability tensor components, $k_{r}$ is the coefficient of relative conductivity $\left(0 \leq k_{r} \leq 1\right), \mu$ is the dynamic coefficient of viscosity, $\mathrm{p}$ is the pressure of soil moisture, $\mathrm{g}$ is the gravitational acceleration, $z$ is the height of the considered point fluid flow relative to the plane of the compare and $S$ is the volume saturation. formula:

The speed of movement of water obeys the generalized Darcy's law and is calculated by the

$$
v_{i}=-k_{r} k_{i j}^{f}\left[\frac{\partial}{\partial x_{j}}\left(\frac{p}{\rho g}\right)+\frac{\partial z}{\partial x_{j}}\right],
$$

where $k_{i j}^{f}$ are the components of the coefficient filtration tensor, which are determined from the ratio:

$$
k_{i j}^{f}=\frac{k_{i j} \rho g}{\mu} .
$$

To uniquely solving equations (4) - (6) were assigned initial and boundary conditions. Typically, the initial conditions specify the distribution of depths and velocities for surface water and pressure distribution of moisture in the soil in the initial time:

$$
h(x, 0)=\varphi_{h}(x), u(x, 0)=\varphi_{u}(x) \text { и } p(x, 0)=\varphi(x),
$$

where $x$ is the vector of spatial coordinates, and $\varphi_{h}, \varphi_{u}, \varphi$ are the defined functions.

For the waves rolled forward to shore as boundary conditions for the shallow water equations, select the corresponding Riemann invariants. Boundary conditions for the storage equation (6) can be the first kind (Dirichletian conditions):

$$
p(x, t)=g_{1}(x, t) \text { at } \Gamma_{1},
$$

or the second type (Neumann):

$$
\left[k_{r} \frac{k_{i j}}{\mu}\left(\frac{\partial p}{\partial x_{j}}+\rho g \frac{\partial z}{\partial x_{j}}\right)\right] n_{i}=g_{2}(x, t) \text { on } \Gamma_{2},
$$

where $g_{l}$ is the specified pressure on border $\Gamma_{l} ; n_{i}$ - is $i$-th vector component of external normal to border $\Gamma_{2}$; and $g_{2}$ is the known flow along the external normal to border $\Gamma_{2} ; \Gamma_{1}$ и $\Gamma_{2}$ form a full border of modelling area (Fig.10). 
In the zone of running waves to the shore is quite a complex interaction of waves with groundwater. To describe this interaction, it is used a system of three equations. The first two is a shallow water equations (equations or Saint-Venan) simulated the movement of waves on a slope. The third equation is the equation of moisture transport (or, as it is often called, Richards ' equation) describe the unloading of groundwater to reservoir.

For the numerical solution, the equations of shallow water were approximated by the apparent conservative differential scheme of Godunov's type.

The transport equation approximated by implicit conservative differential scheme. Because of this was the system of nonlinear equations, Newton method was applied.

Usually $\Gamma_{l}$ border is a common border of underground stream with surface water bodies and boundary $\Gamma_{2}$ is characterized by ongoing value through it flow (for example, impenetrable borders, infiltration and evapotranspiration, field and constant injection of fluids).

When unloading groundwater water to the reservoir near water level it is usually formed intervals of slow flowing (everyone could watch them on the banks of water bodies. These dark strips of soil near the water line). These intervals are characterized by the fact that the pressure of moisture in the pores on the surface of the soil, equal to atmospheric one. Value of these gaps in advance is unknown, and it can change over time, so it too is determined from the solution of the problem. And boundary conditions in the form of a water line near the inequities and enable you to find those intervals.

In the instant case, the boundary conditions for the transport equation on the bottom surface are of the form (as shown in Figure 10):

$$
\begin{gathered}
p+\rho g z=P_{a}+\rho g h+\rho u^{2} / 2, \text { on } \mathrm{AB} \text { и ВС; } \\
-\frac{\mathbf{k} k_{r}}{\mu} \frac{\partial}{\partial n}(p+\rho g z)=0, p<P_{a} \text { on } \mathrm{DE} \\
-\frac{\mathbf{k} k_{r}}{\mu} \frac{\partial}{\partial n}(p+\rho g z)>0, p=P_{a}, \text { on } \mathrm{CD}
\end{gathered}
$$

where $n$ is external unit vector normal to the surface of the Earth, $\eta ; P_{a}$ is the atmospheric pressure.

Note that the segment $C D$ is not known in advance and must be determined from the solution. For the numerical solution of equations of Saint-Venan used a clear conservative second-order type Godunov's scheme, and for modelling the movement of water in a porous media - implicit conservative scheme of second order on spatial variables, and first for the time. Calculated values of run-up of waves on slope were obtained with the following filtration characteristics (run-up of waves on the shore is related depending on filtration characteristics of coverage):

$\begin{array}{cll}\text { Layer } & \mathbf{E} & \mathbf{A} \\ \text { Filtration coefficient, cm/s } & 30 & 20 \\ \text { Porosity (bulk) } & 0.48 & 0.42\end{array}$

Manning roughness coefficient taken equal to 0.02 . The results of calculations on a slope waves run-up for the conditions of the experiments in the flume are presented in Table 9.

Fig. 11 shows an example of numerical calculation waves run-up on slope for the conditions of the experiment and coated A (blue marked shows the level of saturation).

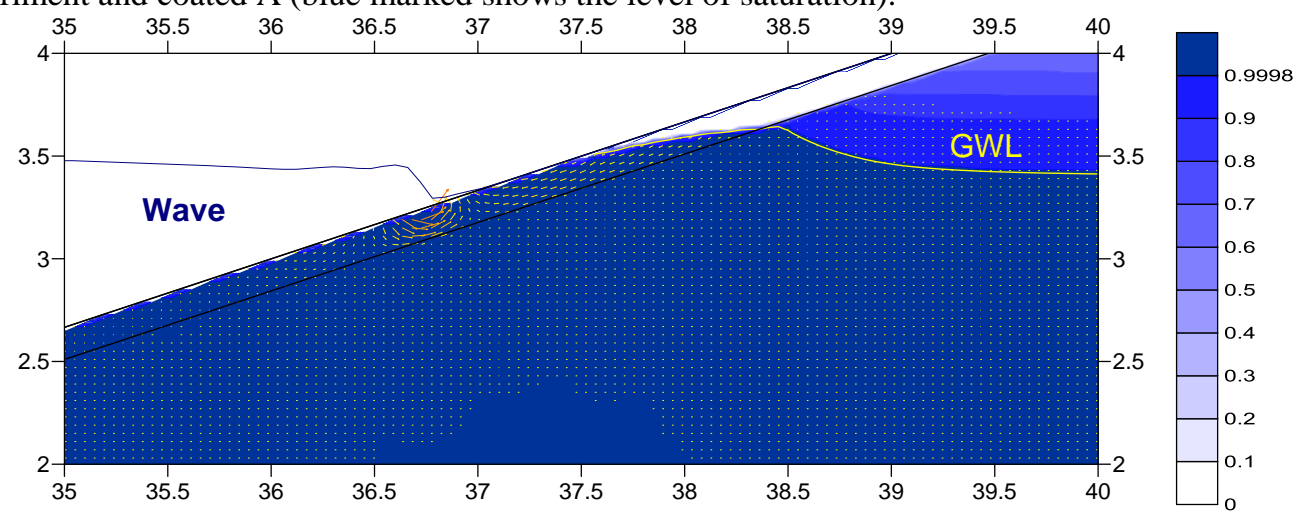

$\mathbf{T}=12 \mathrm{~s}$

Figure 11. The results of numerical calculation of roll waves on permeable anchored slope. For the data of the experiment in a large wave flume in Hannover 


\begin{tabular}{|c|c|c|c|c|c|c|c|c|c|c|c|c|c|c|c|}
\hline No. of test & $\begin{array}{l}h, \\
\mathrm{~m}\end{array}$ & $\begin{array}{c}H_{m} \\
\mathrm{~m}\end{array}$ & $\begin{array}{c}T_{m} \\
\mathrm{~s}\end{array}$ & $\xi_{m}$ & $\frac{\boldsymbol{R}_{u}^{(2)}}{\boldsymbol{H}_{m}}$ & $\frac{\boldsymbol{R}_{u}^{\text {simu }}}{\boldsymbol{H}_{m}}$ & $\frac{\boldsymbol{R}_{d}^{s i m u}}{\boldsymbol{H}_{m}}$ & $\frac{\boldsymbol{R}_{u}^{A}}{\boldsymbol{H}_{m}}$ & $\frac{{ }^{A} \boldsymbol{R}_{u}^{\text {simu }}}{\boldsymbol{H}_{m}}$ & $\frac{\boldsymbol{R}_{d}^{A}}{\boldsymbol{H}_{m}}$ & $\frac{{ }^{A} \boldsymbol{R}_{d}^{\text {simu }}}{\boldsymbol{H}_{m}}$ & $\frac{\boldsymbol{R}_{u}^{B}}{\boldsymbol{H}_{m}}$ & $\frac{{ }^{B} \boldsymbol{R}_{u}^{\text {simu }}}{\boldsymbol{H}_{m}}$ & $\frac{\boldsymbol{R}_{d}^{B}}{\boldsymbol{H}_{m}}$ & $\frac{{ }^{B} \boldsymbol{R}_{d}^{s i m u}}{\boldsymbol{H}_{m}}$ \\
\hline 1 & 2 & 3 & 4 & 5 & 6 & 7 & 8 & 9 & 10 & 11 & 12 & 13 & 14 & 15 & 16 \\
\hline 09051301 & 3.4 & 0.22 & 3.00 & 2.67 & 2.33 & 2.23 & -1.12 & 1.39 & 1.41 & -0.82 & -0.23 & 1.12 & 1.33 & -0.71 & -0.24 \\
\hline 09051302 & 3.4 & 0.19 & 4.00 & 3.77 & 2.87 & 2.44 & -2.03 & 1.85 & 1.63 & -1.37 & -1.55 & 1.77 & 1.56 & -1.29 & -1.33 \\
\hline 09051303 & 3.4 & 0.21 & 5.00 & 4.59 & 3.11 & 2.49 & -2.19 & 1.83 & 1.79 & -1.59 & -1.73 & 1.67 & 1.72 & -1.52 & -1.62 \\
\hline 09051401 & 3.4 & 0.18 & 5.93 & 5.78 & 3.67 & 2.56 & -2.24 & 2.06 & 1.72 & -1.82 & -1.92 & 1.79 & 1.67 & -1.77 & -1.84 \\
\hline 09051402 & 3.4 & 0.22 & 7.00 & 6.24 & 3.64 & 2.37 & -2.01 & 2.16 & 2.31 & -1.67 & -1.80 & 2.00 & 2.12 & -1.61 & -1.75 \\
\hline 09051403 & 3.4 & 0.17 & 7.90 & 7.94 & 4.46 & 2.12 & -1.84 & 1.83 & 1.75 & -1.86 & -1.85 & 1.70 & 1.83 & -1.81 & -1.86 \\
\hline 09051404 & 3.4 & 0.65 & 3.00 & 1.55 & 1.76 & 1.30 & -0.01 & 1.23 & 1.33 & 0.03 & -0.05 & 1.24 & 1.34 & -0.04 & -0.03 \\
\hline 09051405 & 3.6 & 0.68 & 4.01 & 2.02 & 1.93 & 1.81 & -0.19 & 1.68 & 1.85 & -0.03 & -0.08 & 1.70 & 1.76 & -0.20 & -0.14 \\
\hline 09051406 & 3.6 & 1.04 & 3.00 & 1.22 & 1.61 & 1.24 & 0.34 & 0.89 & 1.12 & 0.24 & 0.29 & 0.92 & 1.04 & 0.26 & 0.31 \\
\hline 09051501 & 3.7 & 0.64 & 4.95 & 2.57 & 2.11 & 2.00 & -1.08 & 1.79 & 1.85 & -0.36 & -0.72 & 2.00 & 1.79 & -0.53 & -0.60 \\
\hline 09051502 & 3.7 & 1.14 & 3.92 & 1.53 & 1.71 & 1.51 & 0.31 & 1.39 & 1.52 & 0.28 & 0.33 & 1.45 & 1.60 & 0.35 & 0.33 \\
\hline 09051503 & 3.7 & 1.40 & 3.92 & 1.38 & 1.65 & 1.43 & 0.36 & 1.22 & 1.24 & 0.29 & 0.36 & 1.28 & 1.19 & 0.41 & 0.39 \\
\hline 09051504 & 3.9 & 0.65 & 6.00 & 3.10 & 2.27 & 2.31 & -1.97 & 2.07 & 2.20 & -0.50 & -0.72 & 2.13 & 2.13 & -0.72 & -0.75 \\
\hline 09051505 & 3.9 & 0.54 & 6.93 & 3.91 & 2.55 & 2.38 & -2.10 & 2.15 & 2.22 & -0.90 & -1.01 & 2.17 & 2.31 & -1.14 & -1.12 \\
\hline 090511801 & 3.9 & 0.55 & 7.98 & 4.49 & 2.67 & 2.19 & -1.93 & 2.18 & 2.12 & -1.13 & -1.42 & 2.22 & 2.17 & -1.28 & -1.37 \\
\hline 090511802 & 3.9 & $\mid 1.37$ & 4.90 & 1.75 & 1.76 & 1.68 & 0.15 & & & 0.32 & & 1.81 & & 0.36 & \\
\hline
\end{tabular}

Note: the ratio $\frac{\boldsymbol{R}_{u}^{(2)}}{\boldsymbol{H}_{m}}$ calculated under formulas (2), (3), "simu" indicates the result of the numerical simulation, the coating type specified: "A" or "B", the absence of such marking relates the result to the conditions of the smooth impermeable slope

\section{Comparison of results of numerical and laboratory studies}

To check the results of the simulation, height values compared with the waves run-up available experimental data. Figs 12 and 13 compares the results measured and received by numerical simulation of run-up heights and run-down of waves on a fixed permeable slope. Fig. 12 comparison refers to the height of run-up, as in Fig. 13- the height of run-down the waves, respectively. The same figures are the regression lines, indicating the degree of agreement measured in the laboratory and obtained numerical data experiences. The figures show the horizontal axis measurement data in accordance with table 9 , and the vertical axis numerical simulation data are also presented in table 9.

Analysis of these results indicates that the numerical model satisfactorily consistent with data used in large-scale experiments in the wave flume. 


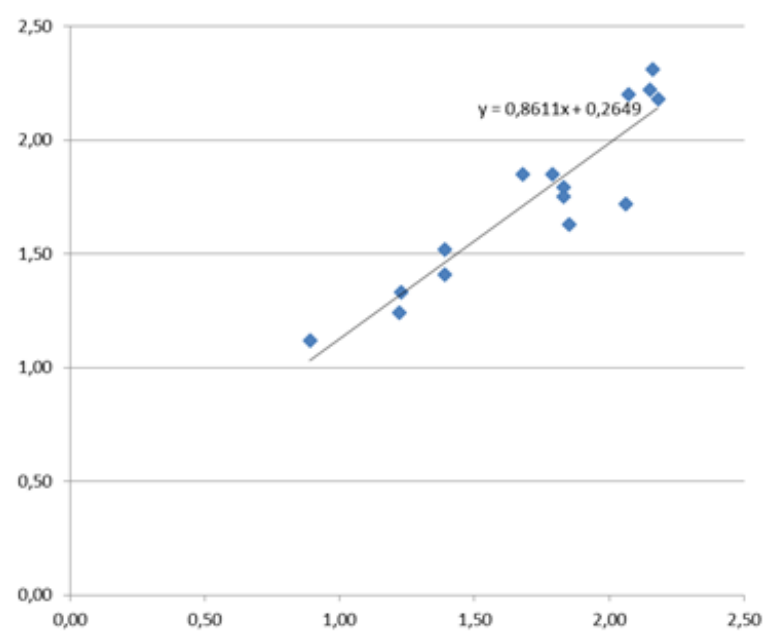

Figure 12. Comparing data on height of run-up of waves on permeable fixed slope obtained by measurements in the wave flume and numerical simulation

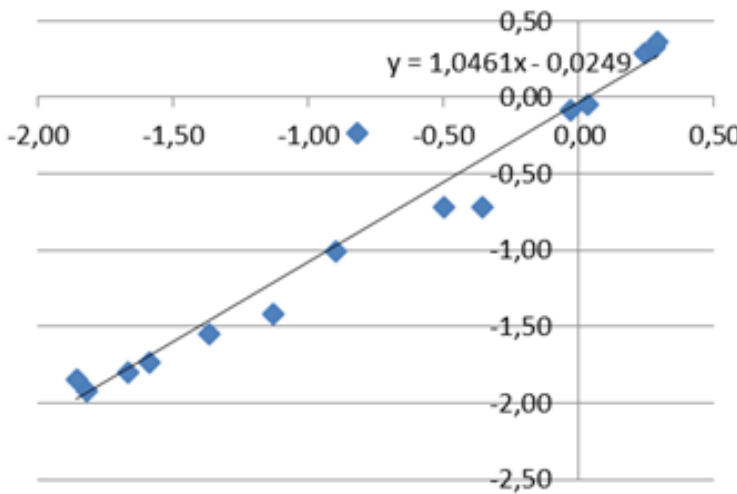

Figure 13. Comparison of height data run-down of waves on permeable fixed slope obtained measurements in the wave flume and numerical simulation

\section{CONCLUSION}

For permeable fixed protective coating, the top protective layer can be considered as porous media. That allowed the development of a numerical model of run-up of waves on slope, considering the interaction flow of run-up on the surface slope and filtration flow in porous protective layer. The developed numerical model of run-up of waves on slope, allows you to receive necessary for designing structures slope structures with permeable top layer, run-up and run-down of waves. It is possible to determine the position of the free wave surface (value of run-up of waves on slope and elevation waves with a run-down from a slope) at different points in time, necessary to calculate the top mark of slope construction with permeable top layer.

The developed numerical model verified by comparison with data published full-scale experiments performed in the wave flume at the Technical University of Braunschweig, Hannover, Germany. Satisfactory results of the comparison are obtained. 


\section{REFERENCES}

Alcerreca, H.J.C., and H. Oumeraci. 2012. Interaction of Waves with a Porous Bonded Revetment and its Foundation: Process-based modelling, LWI. TU Braunschweig, Progress Report no 02: Numerical model in OpenFOAM (LWI-FOAM): Model equations and validation tests, 68 pp.

Compilation of the Technical Design Guidelines for Elastocoast. 2010. BASF Polyurethanes GmbH, Report No 90154-01, 73 pp.

Experimental Projects with Elastocoast System in Holland in Storm Period 2007/2008. 2008. ASTOGRAN GBH, 99 pp.

Hydraulic Performance, Wave Loading and Response of Elastocoast and their Foundation. A LargeScale Model Study (Final Report). 2010. LWI Report no.988, Technische Universität Braunschweig. Leichtweiß-Institut für Wasserbau. Braunschweig. 176 pp.

Hughes S.A. 2004. Estimation of run-up on smooth, impermeable slopes using the wave momentum flux parameter, Coastal Engineering, 51, p. 1085-1104.

Jeleznyak M.I., and E.N. Pelinovsky. 1985. Physical-mathematical models of tsunami run-up on a shore. In: Tsunami run-up the shore. Gorky, USSR Academy of Sciences, pp. 8-34.

Jeleznyak M.I., I.G. Kantarzhi, I.O. Leont'ev, and V.M. Shakhin. 2011. Mathematical modeling of coastal processes in Imeretinka lowland to base the coastal protection. Hydraulic Structures, no.10, p. 22-29.

Kantardgi I.G., S.L Kivva, and N. V. Shunko. 2014. Wave run-up on permeable fixed reveted slopes, Magazine of Civil Engineering, No.6, p. 13-23.

Lappo D.D., S.S.Strekalov, and V.K. Zavialov. 1990. Loads and Effects on Hydraulic Structures. Leningrad, VNIIG, $432 \mathrm{pp}$.

Liebisch S., H.J.C. Alcerreca, A. Kortenhaus, and H. Oumeraci. 2012. Bonded porous revetments effect of porosity on wave-induced loads and hydraulic performance. Proc. Int. Conf. on Coastal Engineering. ICCE, Santander, Spain.

Muttray M., H. Oumeraci, K. Shimosako, and S. Takahashi. 1998. Hydraulic performance of high mound composite breakwater. Proc. Int. Conf. of Coastal Engineering. ICCE., Copenhagen, Denmark.

Muttray M., and H. Oumeraci. 2005. Theoretical and experimental study on wave damping inside a rubble mound breakwater. Coastal Engineering, vol.52, No.8.

Neves Diogo R.C.B., E. Didier, M.T. Reis, and M.G. Neves. 2012. Overtopping of a porous structure using a smoothed particle hydrodynamics numerical model. Proc. $4^{\text {th }}$ Int. Conf. of the Application of Physical Modelling to Port and Coastal Protection. Coastlab12. Ghent, Belgium, Sep.17-20. p.531-540

Oumeraci H., T. Staal, S. Pfoertner, M. Kudella, S. Schimmels, and H.H. Verhagen. 2010. Hydraulic performance of elastomeric bonded permeable revetments and subsoil response to wave load. Proc. Int. Conf. on Coastal Engineering (ICCE), Shanghai, China.

Oumeraci H. 2012. More than 20 years' experience using the re-search facility "Grosser Wellenkanal (GWK)": Selected research projects \& lessons learning. Proc. $4^{\text {th }}$ Int. Conf. of the Application of Physical Modelling to Port and Coastal Protection. Coastlab12, Ghent, Belgium, Sep.17-20, 2012. p.28-64.

The Elastocoast System. 2008. A Study of Possible Failure Mechanisms. MSc. Thesis Report of E. Bijlsma. Delft University of Technology. 141 pp. 